\title{
A EDUCAÇÃO AMBIENTAL COMO PROPOSTA DE FORMAÇÃO DE PROFESSORES REFLEXIVOS: DAS PRÁTICAS CONTEXTUALIZADAS À AMBIENTALIZAÇÃO NO ENSINO DE CIÊNCIAS
}

\author{
Maria Luciana da Silva Nóbrega \\ Universidade Federal do Vale do São Francisco (UNIVASF), \\ São Raimundo Nonato, Piauí, Brasil \\ Maria das Graças Cleophas \\ Universidade Federal da Integração Latino-Americana \\ (UNILA), Foz do Iguaçu, Paraná, Brasil
}

\begin{abstract}
Resumo: A Educação Ambiental tem contribuído para uma aprendizagem significativa, inserindo nas práticas pedagógicas uma reflexividade na construção do conhecimento. No intuito de promover a Ambientalização dos espaços de aprendizagem, muitos educadores buscam inserir novas metodologias na abordagem dos conteúdos de sala de aula. Nesse sentido, utilizando as práticas pedagógicas da Contextualização dos Conteúdos, da Convivência com o Meio e da Interdisciplinaridade, foi realizada uma atividade, no âmbito do programa PIBID, com licenciandos do curso de Ciências da Natureza. O objetivo foi estimulá-los a adotar práticas diferenciadas na abordagem dos conteúdos de Ciências e, em seguida, refletir sobre a eficácia dessas práticas na promoção da Ambientalização e da Sustentabilidade no âmbito escolar. Como resultado, foi revelado a disposição dos licenciandos em utilizar as paisagens do Piauí na contextualização e interdisciplinaridade de suas práticas pedagógicas.

PalaVRas-chave: Educação Ambiental. Aprendizagem. Ambientalização. Ensino de Ciências.
\end{abstract}




\section{INTRODUÇÃO}

Não devemos chamar o povo à escola para receber instruções, postulados, receitas, ameaças, repreensões e punições, mas para participar coletivamente da construção de um saber, que vai além do saber de pura experiência feito, que leve em conta as suas necessidades e o torne instrumento de luta, possibilitando-Ihe ser sujeito de sua própria história (FREIRE, 2001, p. 35).

A Educação é um amplo campo de forças, de discursos, práticas e debates. Até a determinância de sua própria função social é discutida, seja pelo aspecto da institucionalidade, da relevância e determinação dos conteúdos ensinados/aprendidos, ou das metodologias e suas adequações às demandas sociais, históricas e culturais, entre outros aspectos. A Escola, como espelho da realidade social, reflete diversas óticas e vertentes. Por vezes, as concepções sobre o papel social da escola são totalmente divergentes, podemos encontrar tanto em autores clássicos do século XVII que defendem a excelência da escola enquanto instituição social modelo (COMENIUS, 2011), quanto os opositores dessa visão, como os defensores dos movimentos contemporâneos pela "desescolarização" da sociedade (ILLICH, 1974).

Neste artigo, abordaremos o papel social da Educação para a promoção da emancipação socioambiental. A partir da observância das práticas pedagógicas reflexivas, tais como a Contextualização dos Conteúdos e a Convivência com o Meio Ambiente, procuramos identificar o entendimento dos estudantes e educadores quanto à nova demanda da escola para século XXI: ser um espaço educador sustentável (CZAPSKI; TRAJBER, 2010).

A prática pedagógica tradicional se caracteriza, entre outros elementos, pela prioridade dada à disciplinaridade, atendo-se à sistematização e repasse dos conteúdos, a partir do planejamento de ensino, no qual cada área do conhecimento tem seu espaço e suas metodologias próprias:

A organização disciplinar foi instituída no século XIX, notadamente com a formação das universidades modernas; desenvolveu-se, depois, no século XX, com o impulso dado à pesquisa científica; isto significa que as disciplinas têm uma história: nascimento, institucionalização, evolução, esgotamento, etc. Essa história está inscrita na da Universidade, que, por sua vez, está inscrita na história da sociedade (MORIN, 2002, p. 105).

Contudo, as demandas contemporâneas da Educação vão além da mera apreensão de conteúdos ou cumprimento dos currículos disciplinares 
preestabelecidos numa perspectiva multi ou pluridisciplinar (JAPIASSÚ, 1976). A inserção da interdisciplinaridade, e de suas metodologias, torna-se essencial para se apreender o sentido da complexidade do mundo dos fatos de forma sistêmica, pois "o parcelamento e a compartimentação dos saberes impedem apreender o que está tecido junto" (MORIN, 2000, p.45). Segundo os Parâmetros Curriculares Nacionais (PCNs):

A interdisciplinaridade supõe um eixo integrador, que pode ser o objeto de conhecimento, um projeto de investigação, um plano de intervenção. Nesse sentido, ela deve partir da necessidade sentida pelas escolas, professores e alunos de explicar, compreender, intervir, mudar, prever, algo que desafia uma disciplina isolada e atrai a atenção de mais de um olhar, talvez vários (BRASIL, 2002, p. 88-89).

No ensino de Ciências, esse parcelamento e compartimentação dos saberes foram adotados, inicialmente, como uma metodologia de apresentação dos conteúdos específicos a cada área. Contudo, o esfacelamento da Ciência, como saber complexo, foi um dos resultados inevitáveis. A falta de "diálogo" entre as distintas áreas do conhecimento e dessas com a dinâmica da vida escolar, trouxe alguns problemas para o ensino das Ciências, pois produziu uma dicotomia entre o conhecimento teórico e sua aplicação prática no mundo das ações.

Uma das abordagens deste presente artigo é o papel da Educação na promoção da Ambientalização: dos docentes, dos discentes e da sociedade como um todo. Para tratar da emancipação socioambiental temo que nos remeter a uma estratégia indispensável: a Contextualização dos Conteúdos, referenciados pela perspectiva socioambiental (NÓBREGA, 2012). Além da preocupação com a prática socioambiental, a Ambientalização também estimula a complexidade e a interdisciplinaridade (LUZZI, 2003), essencial à compreensão das inter-relações Homem-Natureza, através de um pensamento ou uma abordagem sistêmica (BERTALANFFY, 1977; SENGE et al., 1994; MATURANA; VERDEN-ZÖLLER, 2007; NICOLIS;PRIGOGINE, 1977). A abordagem sistêmica defende a educação numa visão holística, que se preocupa com o sujeito e o meio, em uma totalidade; indivíduo e contexto pensados como um conjunto de inter-relações, propondo uma concepção ecossistêmica da realidade.

A Ambientalização é um processo de conscientização e estímulo de práticas sustentáveis desencadeado nas instituições, partindo das ações já existentes em torno da temática socioambiental nestes locais (NÓBREGA; NASCIMENTO, no prelo). Ou seja, é uma ampliação das ações vivenciadas, 
objetivando uma maior inserção dos atores nesse processo, partindo do interesse e do conhecimento prévio dos indivíduos acerca das temáticas socioambientais. Segundo a Rede ACES (Ambientalização Curricular do Ensino Superior), o processo de Ambientalização ocorre quando há uma institucionalização das práticas socioambientais na escola ou universidade e quando há uma participação ampla dos diferentes atores dessa instituição. Sendo assim, "ambientalizar o currículo" significa reapresentar o mesmo conteúdo sob diferentes enfoques teóricos e metodológicos, garantindo que a interdisciplinaridade atue nos currículos de modo direto, favorecendo a inserção das temáticas socioambientais de modo transversal. Para tanto, uma série de mudanças devem ser consideradas:

[...] inovações conceituais, metodológicas e atitudinais, mas também estruturais e organizacionais, que permitam um enfoque interdisciplinar no currículo, que facilite um planejamento global de objetivos e conteúdos, que se aproxime da compreensão da complexidade e da visão planetária [...] que facilitem a descentralização e a flexibilidade do currículo necessárias para adaptar-se ao entorno e dar respostas às suas inquietudes (GONZÁLES MUÑOZ, 1996, p. 37).

A interdisciplinaridade visa uma contextualização dos conteúdos de sala de aula sintonizando-os com as questões pertinentes da realidade da ordem social, política e econômica de cada época (FAZENDA, 1993; JAPIASSÚ, 1976; SANTOMÉ, 1998). Ela se tornou, sobremaneira, necessária para a compreensão e apreensão da realidade, pelos educandos, que passam a refletir não somente sobre os conteúdos, mas o que fazer com eles, respondendo a inquietações sobre onde, como e quando aplicar os conhecimentos aprendidos em sala. Neste sentido, a sala de aula torna-se o mundo inteiro, incentivando os indivíduos a entenderem outras realidades além da sua própria.

Ao"trazer o mundo" para a sala de aula, muitas práticas pedagógicas fazem o caminho inverso: levam a sala de aula para o mundo. Esta foi a experiência de aplicação prática em Educação Ambiental (EA) registrada neste artigo, uma atividade visando uma aprendizagem significativa, tendo como aporte o uso de conteúdos contextualizados ao território do Parque Nacional Serra da Capivara, localizado na região semiárida do estado do Piauí (Brasil). A partir de uma atividade diferenciada, proposta no âmbito do Programa Institucional de Bolsas de Iniciação à Docência (PIBID/CAPES/MEC), alunos-bolsistas do curso de licenciatura em Ciências da Natureza da Universidade Federal do Vale do São Francisco (UNIVASF), foram estimulados a inserir 
conteúdos sobre EA em suas práticas pedagógicas. O objetivo foi intercalar as abordagens científicas, inerentes às ciências naturais, com os princípios da teoria da convivência com semiárido (NÓBREGA; REIS; CARVALHO, 2011). O intuito foi incorporar nessas abordagens os princípios da cidadania planetária (GUTIÉRREZ; PRADO, 1997), aplicando-as ao território da Serra da Capivara. Os beneficiários dessas práticas foram os estudantes do Ensino Fundamental das escolas contempladas pelas ações do PIBID.

\section{FUNDAMENTAÇÃO TEÓRICA}

\section{1 - Referencials teÓrico-práticos para uma EducaÇão Ambientalizada}

No decorrer da primeira metade do século XX, fortaleceu-se, entre vários estudiosos um movimento em prol de um novo processo de aprendizagem que levasse em consideração as chamadas "abordagens sistêmicas", como um novo paradigma de concepção de mundo, outras abordagens na elaboração do trabalho científico e de novos âmbitos de conhecimento, propondo modificação nas concepções de realidade, de pesquisas e de aprendizagem envolvida na produção da ciência, combatendo o reducionismo e o cartesianismo da compartimentação da Ciência.

Esse novo paradigma apresenta rupturas com o paradigma tradicional da ciência, sobretudo por priorizar o "sujeito do conhecimento" numa dimensão ampliada e integradora, sem a necessidade de um distanciamento dos elementos envolvidos ou uma postura de neutralidade e subjetivismo, mas promovendo uma visão integral da Ciência e da Educação numa perspectiva fazer-saber (MATURANA;VERDEN-ZÖLLER, 2007). Essa abordagem nos leva a enxergar a escola como um espaço de convivência e de aceitação, de construção de diferentes saberes dialógicos e de valorização das experiências e dos conhecimentos prévios. Logo, todo indivíduo e seu saber devem ser respeitados, contribuindo, assim, para a construção de um espaço de saber prazeroso, dinâmico e criativo.

Para compreendermos uma prática pedagógica (socioambientalmente) emancipatória, é necessário abordar os principais referenciais que alicerçam essa construção. Aqui destacamos dois aspectos (e suas abordagens) que se interconectam nesta promoção, conforme ilustra a Figura 1. Defendemos que a junção indissociável dessas quatro perspectivas pedagógicas consti- 
tui interface indispensável para a formação de professores mais reflexivos, contribuindo, deste modo, para uma efetiva busca pela construção de uma cidadania planetária (GURIÉRREZ; PRADO, 1997).

Figura 1 - Quatro perspectivas da prática pedagógica (socioambientalmente) emancipatória.

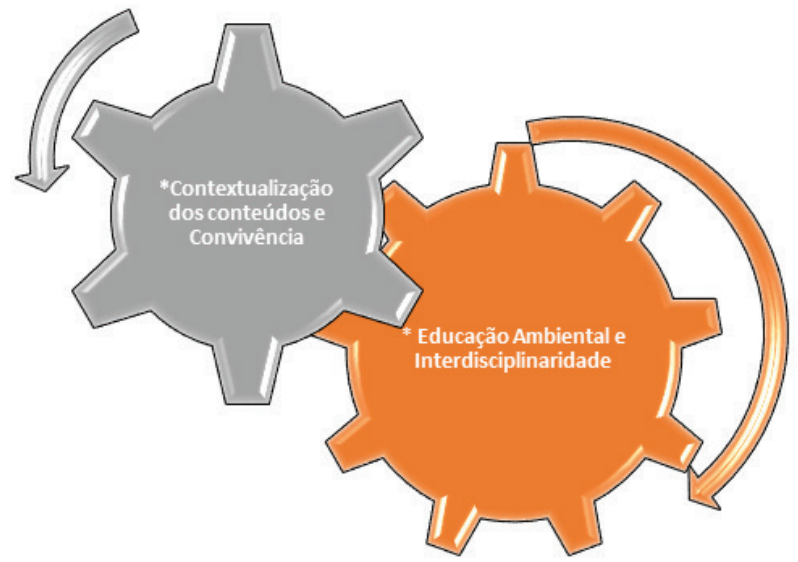

Fonte: Elaborada pelas autoras, 2016.

Outro conceito que fundamenta este trabalho é a pedagogia do professor reflexivo (DEWEY, 1979; ALARCÃO, 1996; 2003), termo que ganhou mais visibilidade a partir dos anos 1990. Para esses autores, o poder de reflexão é o elemento que impulsiona a melhoria das práticas profissionais docentes e que, juntamente com a pesquisa e investigação, promove a problematização da realidade vivida pelos atores sociais. O objetivo é que a atividade da aprendizagem seja distinta de um ato mecânico e rotineiro e que haja uma reflexão sobre as problemáticas reais envolvidas no ensino. Os resultados não estão predeterminados, a investigação é o instrumento principal do professor reflexivo.

\section{2 - EduCAÇÃo Ambiental (EA) e INTERDISCIPLINARIDAde}

A Educação Ambiental (EA) é concebida como um processo de aprendizagem contínuo e transversal a todas as áreas do conhecimento, portanto, fundamentalmente interdisciplinar, e deve ser dirigida a todos os grupos de idade e categorias profissionais: 
Ao público em geral, não-especializado, composto por jovens e adultos cujos comportamentos cotidianos têm uma influência decisiva na preservação e melhoria do meio ambiente; aos grupos sociais específicos cujas atividades profissionais incidem sobre a qualidade desse meio; aos técnicos e cientistas cujas pesquisas e práticas especializadas constituirão a base de conhecimentos sobre os quais deve sustentar-se uma educação, uma formação e uma gestão eficaz, relativa ao ambiente (ONU, 1977, p. 1).

A EA ganhou mais efetividade nas escolas a partir da Eco 92 (Conferência das Nações Unidas sobre Meio Ambiente e Desenvolvimento - CNUMAD), quando ficou patente, no documento final da Conferência, a preocupação em se desenvolver métodos e práticas ambientais institucionalizados. Exemplo disso foi a realização do Workshop sobre Educação Ambiental, promovido pelo Ministério da Educação (MEC/Brasil), o único evento oficial, paralelo à CNUMAD, realizado entre 1 e 12 de julho de 1992, em Jacarepaguá, Rio de Janeiro. $O$ evento produziu documentos significativos para a EA: um foi a "Carta Brasileira da Educação Ambiental", que traz dez considerações e quinze recomendações para o desenvolvimento da EA no Brasil; o outro foi o "Tratado de Educação Ambiental para Sociedades Sustentáveis e Responsabilidade Global". Já a Conferência de Tbilisi (1977) recomendou a prática da interdisciplinaridade como a forma mais eficaz de promoção da EA. Por ser transversal, a EA não deve ser restrita a um campo de saber ou a uma (ou algumas) disciplina(s), mas deve englobar todos os campos científicos e áreas do estudo, visando à integração dos saberes, incluindo os saberes populares e tradicionais.

\section{3 - Contextualização dos Conteúdos e da Convivência}

A Educação encontra um significado profundo nos fenômenos sociais e pressupõe o homem como um ser dinâmico, fenomenológico e incompleto, ou seja, que sempre pode ser aprimorado. Necessário é conferir à Educação uma característica pragmática, mas não utilitarista, um caráter de agente transformador quanto às práticas e a atuação na realidade local (NÓBREGA, 2012). Sendo assim, devemos refletir sobre alguns elementos norteadores como: currículo, práticas, formação e capacitação docente, legislação, a fim de perceber se estes estão ambientalizados o suficiente para dar o suporte necessário à Escola enquanto espaço educador sustentável.

A Contextualização na Educação, ou Educação Contextualizada, é uma das primícias do processo de Ambientalização. A Escola passa a ser 
também um espaço de promoção da Cidadania Planetária, numa perspectiva de Desenvolvimento Sustentável, regido pela promoção da convivência com o meio. Logo, a escola tem um papel de extrema relevância, pois contribuiu para a promoção da Sustentabilidade, tanto na formação estudantil, quanto nosurgimento de metodologias diferenciadas para esse mesmo fim.

Para alcançarmos uma proposta em defesa de uma Educação emancipatória que promova uma conscientização socioambiental numa perspectiva planetária, se faz necessário que iniciemos nossas experiências exploratórias partindo do território à nossa volta. É preciso conhecer a realidade que nos cerca, para então intervir e promover ações de efetivo empoderamento, aprendizagem e Desenvolvimento Sustentável. A vivência dos conteúdos científicos in loco é uma grande oportunidade de estímulo ao estudo e assimilação desses conteúdos, é a base para uma aprendizagem significativa (AUSUBEL, 1982). Nesse sentido, a Convivência é um aspecto fundamental na construção de nosso referencial teórico.

A teoria da aprendizagem de Ausubel propõe que os conhecimentos prévios dos alunos sejam valorizados para que seja possível elaborar estruturas mentais, utilizando, como meio, mapas conceituais que permitam descobrir e redescobrir outros conhecimentos, caracterizando, assim, uma aprendizagem prazerosa e eficaz (PELIZZARI et al., 2002).

Uma proposta diferenciada para assimilação de conteúdos é sempre um desafio à parte. Perguntas tendem a pulular a mente dos professores:

- "Como ministrar o conteúdo programático e ainda assim dotá-lo de significado e relevância?"

- "Quais ferramentas devo utilizar para promover em sala de aula o aspecto da contextualização?"

Além dessas, deveríamos acrescentar mais uma pergunta, referente à reflexão de nossas práticas pedagógicas atuais:

- "Como transformar o processo de aprendizagem em uma promoção dos aspectos da emancipação e cidadania, especialmente despertar a consciência ecológica para uma cidadania planetária?"

Foi pensando nessa questão que propusemos aliar os conteúdos científicos às práticas da EA, buscando a Contextualização dos Conteúdos e da Convivência.

Dificilmente teremos práticas eficazes de estímulo à consciência socioambiental, se forem elaboradas de forma descontextualizada, desassociadas de aprendizagens significativas e desprovidas de uma intenção socioconstrutivista que valorize o conhecimento prévio dos educandos, inclusive 
o popular e local. A cidadania planetáriaou a emancipação socioambiental compreende inúmeras responsabilidades para um ambiente ecologicamente equilibrado, um compromisso assumido tanto com a comunidade quanto com o ecossistema planetário.

Para Gutiérrez e Prado (1997), a cidadania planetária e a Sustentabilidade são frutos de um processo pedagógico. Partindo do cotidiano, do resgate da sensibilidade, da intuição, das emoções, das alegrias, do amor e da satisfação, é possível compreender o significado do ato de promover a aprendizagem a partir da vida. Esse propósito seria alcançado com a"Ecopedagogia", educando para a vida planetária, onde os indivíduos seriam ensinados a "entender e exigir os seus direitos e exercer suas responsabilidades" (GUTIÉRREZ; PRADO, 1997, p. 14). Cultivando a responsabilidade, como um princípio do dever consciente cidadão.

A contribuição da Ecopedagogia seria incentivar os educandos e professores a trabalhar conjuntamente para a construção de um ambiente equilibrado. Essa relação se constrói coletiva e diariamente, baseada em compromissos entre os grupos sociais e também no âmbito pessoal, promovendo uma consciência de "si" e do"outro". Quando esses valores são internalizados, a conscientização da dimensão planetária adquire engajamento e compromisso individual. Sendo assim, esse processo depende do papel multiplicador e contínuo da escola, dentre outros, para promover a aproximação da natureza e de si, pois:

Distanciar-se da natureza e do "natural" significa distanciar-se de uma parte daquilo de que o'eu'é feito. Sua 'identidade','aquilo que é o eu individual', e, consequentemente, o sentido de self e de auto-respeito, todas essas coisas acabam se desintegrando (NAESS, 1982, p. 164).

\section{Delineamento Metodológico}

Da Teoria à Prática: aspectos metodológicos e experiência de AmbientalizaçÃo no Parque Nacional Serra da Capivara

A pesquisa a que nos referimos neste artigo, e que versa sobre a experiência de aplicação da metodologia de Ambientalização no Ensino de Ciências, foi realizada no segundo semestre do ano de 2013, com 29 alunos do curso de licenciatura em Ciências da Natureza, da Universidade Federal 
do Vale do São Francisco (UNIVASF), câmpus São Raimundo Nonato, Piauí, Brasil. A atividade planejada fazia parte das ações que estavam sendo desenvolvidas no âmbito do PIBID e teve duração de duas semanas, onde, ao longo deste período, foram realizadas inúmeras discussões sobre a temática desta pesquisa com todos os envolvidos no programa (Professores do Ensino Superior, alunos em formação inicial, professores da educação básica), visitas ao Parque, construção de Portfólio,construção de práticas sobre EA, entre outras. Logo, os estudantes que fizeram parte desta pesquisa, eram bolsistas do Programa Institucional de Bolsa de Iniciação à Docência (PIBID/ CAPES/MEC). É importante destacar que o PIBID, segundo Silveira (2015), é um programa que visa garantir que os discentes dos cursos de licenciatura se aproximem da escola e, assim, conheçam algumas práticas pertencentes ao campo profissional, favorecendo assim, que estes sejam capazes de edificar reflexões sobre essas práticas e os saberes que as baseiam.

Os procedimentos utilizados para a coleta e análise de dados foram divididos em duas etapas distintas, visando uma melhor sistematização das informações coletadas durante a execução da atividade proposta. No primeiro momento foi aplicado um questionário elaborado de acordo com os objetivos da investigação. Nele foram estruturados enunciados relacionados às diferentes dimensões sobre as concepções investigadas nos estudantes em relação às práticas de EA aplicadas por estes nas escolas parceiras do PIBID. Como se sabe, um questionário pode ser elaborado utilizando vários tipos de questões e sua escolha é influenciada pelo objetivo que se deseja alcançar (CLEOPHAS; LINS; LEÃO, 2013). O questionário aplicado continha seis questões, e cada uma delas trazia quatro itens de Likert, sem o ponto neutro, apresentando respostas que variavam de concordo plenamente e concordo a discordo e discordo plenamente.

O segundo momento consistiu na execução de entrevistas com os sujeitos participantes desta pesquisa (alunos em formação inicial). Para a entrevista, foi elaborado um roteiro contendo questões semiestruturadas sobre as práticas de EA adequadas ao ambiente escolar, a inserção dessas práticas e um breve relato dessas experiências no contexto da escola. Para análise destes dados obtidos, recorremos à análise textual discursiva, baseada no trabalho de Moraes e Galiazzi (2006). Esta pesquisa apresenta caráter qualitativo, contudo, utilizamos questionários do tipo Survey com escala Likert para obter descrições quantitativas acerca dos resultados. Acreditamos que tal metodologia possa contribuir com as novas compreensões fenomenológicas sobre a temática em questão. 


\section{Resultados Obtidos}

Os resultados obtidos por esta pesquisa serão discutidos em etapas, visando sua melhor sistematização. A primeira etapa consiste na discussão sobre os resultados adquiridos a partir do questionário elaborado e aplicado.

1a ETAPA: DISCUSSÃO dOS DADOS OBTIDOS A PARTIR DA APLICAÇÃO dO QUESTIONÁRIO:

Figura 2 - Gráficos referentes aos dados coletados para as questões 1 e 2.

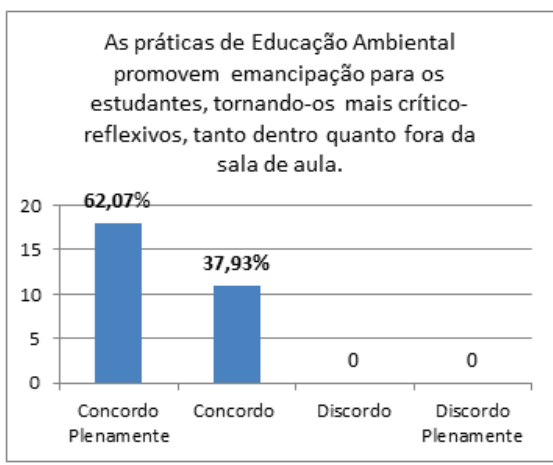

Questão 1

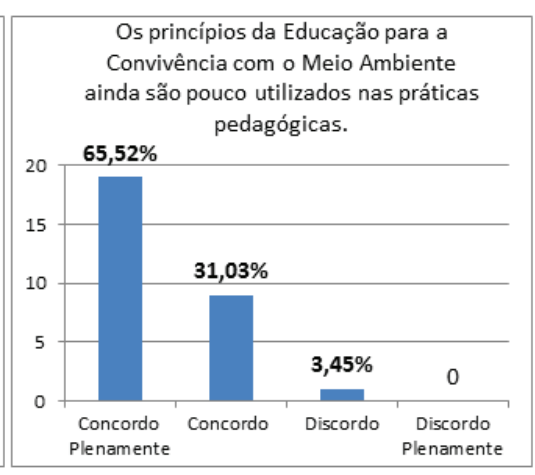

Questão 2

Fonte: Elaborada pelas autoras, 2016.

O gráfico referente à Questão 1, mostra que $62,07 \%(n=18)$ dos discentes concordam plenamente que "as práticas sobre Educação Ambiental promovem emancipação para os estudantes, tornando-os mais críticos-reflexivos, tanto dentro quanto fora da sala de aula". Esse resultado mostra que é significante o número de estudantes conscientes dessa necessidade formativa. Para estes futuros professores, diante do seu processo em formação inicial, tal resultado nos fornece indícios que a EA pode promover mudanças de atitudes perante o contexto social no qual estes sujeitos estão inseridos.

A Questão 2 exibe que 65,52\% ( $n=19)$ dos discentes entrevistados concordam plenamente que "os princípios da Educação para a Convivência com o Meio Ambiente ainda são pouco utilizados nas práticas pedagógicas". Provavelmente, a falta de um diálogo interdisciplinar mais eficaz durante a formação inicial dos alunos contribuiu com a afirmativa acima. Segundo Tardif (2002), neste processo de formação para o magistério, há o domínio, sobretudo, de conhecimentos disciplinares, o que corrobora o conceito de 
prática pedagógica, dado por Cordeiro (2010), que diz que ela pode ser considerada como sendo o trabalho de repassar ou transmitir os saberes específicos. Para Brito (2006), a prática pedagógica significa refletir sobre a necessidade de articulação entre teoria e prática, compreendendo, assim, a trajetória profissional, vivenciada no contexto da sala de aula, como possibilitadora de aprendizagens sobre a profissão.

Figura 3 -Referente aos gráficos que exibem os dados coletados para as questões 3 e 4.

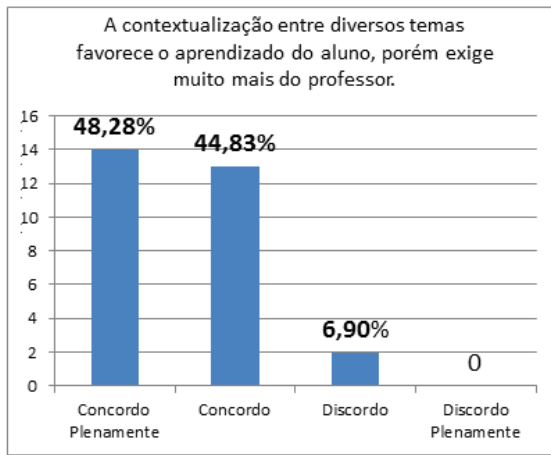

Questão 3

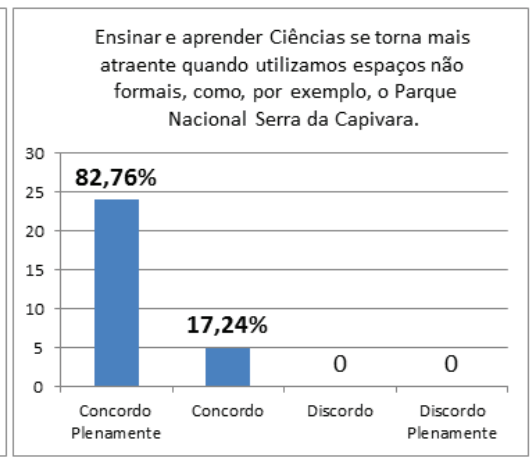

Questão 4

Fonte: Elaborada pelas autoras, 2016.

A Questão 3 versa sobre a importância da contextualização de diversos temas em sala de aula e as dificuldades de aplicá-la. Essa questão, praticamente, apresentou um empate técnico de opiniões. Logo, 48,28\% ( $n=14)$ dos entrevistados concordam plenamente com a assertiva 3, contra $44,83 \%$ $(n=13)$ que apenas concordam com tal questão. A Contextualização é um processo que reflete sobre as atitudes de um professor. Para contextualizar, é preciso dominar com mais rigor os temas trabalhados em sala de aula,além de possuir várias leituras sobre diferentes aspectos sociais, econômicos, políticos, geográficos, dentre outros. Tal situação fortalece que o ato de contextualizar "traz consequências sociais, culturais, políticas, econômicas, cognitivas, linguísticas, quer para o grupo social em que seja introduzida, quer para o indivíduo que aprenda a usá-la" (SOARES, 2001, p.18).

A Questão 4 objetivou extrair dos entrevistados questões sobre a importância de usufruir a biodiversidade que os cercam, com o intuito de promover o ensino e aprendizagem das Ciências Naturais. A Serra da Capivara possui cenários exuberantes, além da singularidade arqueológica. Tal terri- 
tório permite que professores possam utilizá-lo para a promoção de práticas educativas de convivência com esse ecossistema, favorecendo o aprendizado de conceitos que estão imbuídos nos diversos componentes curriculares do curso de Ciências da Natureza. Como sabemos, a educação em espaços nãoformais abre possibilidades de conhecimento sobre o mundo que rodeia os indivíduos e suas relações sociais (CLEOPHAS et al., 2011). Desse modo, percebeu-se que $82,76 \%(n=24)$ dos entrevistados acreditam que "ensinar e aprender Ciências se torna mais atraente quando se utilizam espaços nãoformais, como, por exemplo, o Parque Nacional Serra da Capivara". Assim, para Rocha e Fachín-Terán (2010), a educação científica ganhará muito a partir das práticas pedagógicas nesses espaços, tendo em vista que a educação nãoformal como processo educacional, com objetivos definidos, mantém uma flexibilidade com relação ao tempo, aos objetivos e conteúdos propícios da aprendizagem. Cleophas (2016) complementa ainda que o ensino em espaços não formais favorece a construção de diferentes situações didático-pedagógicas, configurando-se em um "espaço" importante para transformaro saber cotidiano dos alunos em um saber científico.

Figura 4 - Referente aos gráficos que exibem os dados coletados para as questões 5 e 6.

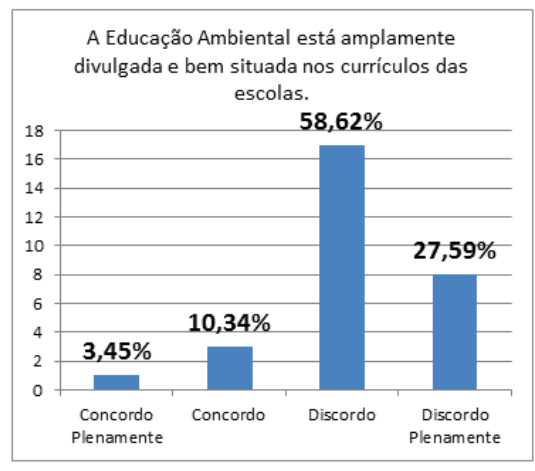

Questão 5

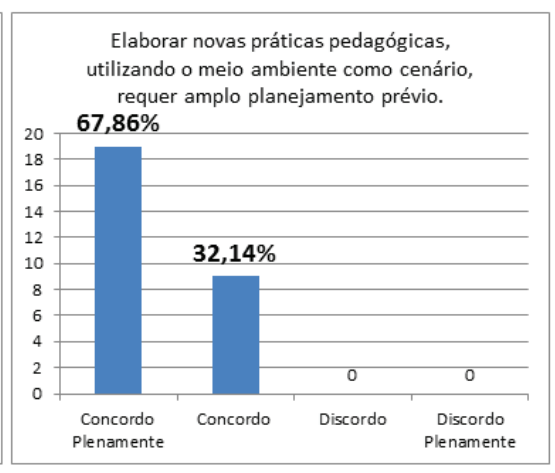

Questão 6

Fonte: Elaborada pelas autoras, 2016.

A Questão 5 teve como meta fazer emergir ou fomentar a criticidade dos entrevistados. A assertiva "a Educação Ambiental está amplamente divulgada e bem situada nos currículos das escolas" nos mostrou que essa questão é um pouco divergente entre os respondentes, pois $58,62 \%(n=17)$ discordam da assertiva, enquanto $27,59 \%(n=08)$ discordam completamente, 
$10,34 \%$ ( $n=03$ ) concordam e $3,45 \%$ ( $n=01)$ concordam plenamente com tal afirmação, mostrando que existe uma dicotomia entre a realidade escolar e os documentos escolares. Estes documentos devem ser frutos de uma construção coletiva, onde os aspectos sociais, regionais e locais possam ser enaltecidos, de modo a contribuir mais eficazmente com a mudança de valores de todos os que formam o ambiente escolar. A partir desse cenário de incorporação da EA nos currículos, das reformas nos sistemas educativos e da necessidade de efetivação das mesmas nas práticas docentes, é importante remarcar que os conhecimentos escolares são decorrentes de um processo de construção social, ao mesmo tempo compartilhados e negociados entre os diversos grupos que compõem esta dinâmica (TARDIF, 2002), ou seja, todos devem ser responsáveis por essa mudança de valores, não ficando apenas a cargo do professor.

No tocante ao papel do professor no processo de inserção ou potencialização da EA na escola, a sua função é mediadora, pois se constitui em uma tarefa de grande complexidade, já que a ação não se dá de forma unidirecional (ter somente os alunos como meta), mas de forma multidirecional, relacionando tanto os alunos, os professores, como a comunidade escolar (ANDRADE, 2001).

Finalmente, a assertiva dada pela Questão 6 nos fornece indícios sobre a dificuldade de inserção de práticas pedagógicas utilizando o meio ambiente. Ao todo, $67,86 \%(n=20)$ dos entrevistados possuem consciência da necessidade de planejar-se com antecedência para a prática pedagógica que se deseja aplicar. A prática pedagógica elaborada pelo professor deve favorecer a conscientização sobre os problemas ambientais existentes no contexto socioambiental em que o seu aluno está inserido. Dias (1998) defende que a inserção de práticas ambientais deve promover o desenvolvimento de conhecimento, de atitude e de habilidades necessárias à preservação e melhoria da qualidade ambiental, pois a função do trabalho didático envolvendo o tema meio ambiente é contribuir para a formação cognitiva e social do aluno, o que favorece, sobretudo, na formação de sujeitos mais críticos e conscientes do seu papel na sociedade, promovendo melhorias que possam ser aplicadas no meio em que vivem.

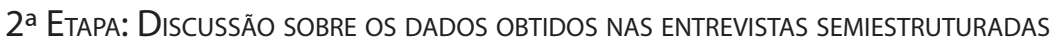

Com a análise textual discursiva sobre os dados obtidos nas entrevistas, buscou-se construir novos significados sobre o tema em questão. 
Selecionamos fragmentos textuais, pois julgamos pertinentes para a discussão aqui apresentada. Os excertos que serão citados abaixo foram os mais representativos para esta pesquisa. A identificação dos alunos foi dada pelo sistema alfanumérico (W1. W2, W3...Wn).

Os entrevistados foram questionados sobre as seguintes situações:

a) Qual(is) prática(s) de Educação Ambiental você acha que seria(m) mais adequada(s) para a sua escola?

A partir desta proposição, buscamos verificar junto aos professores, ainda em formação inicial, se estavam preocupados com a inserção de práticas em Educação Ambiental, traçando, assim, um perfil sobre as características destes futuros profissionais da docência. Percebemos que existe um predomínio de ações que são consideradas preservacionistas, tal como exibido no Quadro 1, abaixo:

Quadro 1 - Concepções dos professores em formação inicial sobre práticas ambientais adequadas para aplicação nas escolas.

W1 - "Coleta seletiva de lixo, reciclagem, arborização, reativação

da horta escolar, uso adequado da água".

W2 - "O conhecimento adequado do meio em que vive (região semiárida), trabalhando a temática da reciclagem com os materiais que estão em nosso convívio, o desmatamento e a questão das queimadas, conhecendo do rio que está inserido na região de São Raimundo Nonato (Rio Piauí)".

W3 - "Não desperdiçar água; reduzir o uso de energia e optar por fontes renováveis; fazer a coleta seletiva do lixo; utilizar nos veículos o etanol ao invés da gasolina; realizar eventos que possam conscientizar as pessoas sobre a preservação do meio ambiente, etc.".

W4 - "Apresentar a realidade local e desenvolver práticas que melhorem a situação, como, por exemplo, trabalhar a questão do lixo e métodos de reutilização e descarte adequado do lixo".

W5 - "Aulas práticas em campo com a aplicação de pesquisas experimentais, para que o aluno possa colocar em prática o conteúdo teórico trabalhado em sala de aula".

W5 - "Explorar a reserva de proteção ambiental em frente à escola".

W6 - "A deficiência que se verifica no contexto educacional, e particularmente no ensino de Ciências quando se trabalha educação ambiental, se justifica, muitas vezes, por não haver uma clareza do que seja o meio ambiente e educação ambiental. O desafio que se coloca é de formular uma educação ambiental que seja crítica e inovadora em dois níveis: formal e não formal. Assim, ela deve ser acima de tudo um ato político voltado para a transformação social. O seu enfoque deve buscar uma perspectiva de ação holística que relaciona o homem, a natureza e o universo, tendo como referência que os recursos naturais se esgotam e que o principal responsável pela sua degradação é o ser humano".

W7 - "Inserção dessa temática na rotina da escola, incluindo os hábitos diários, em conjunto com toda a comunidade escolar".

W8 - "As práticas ambientais voltadas para o próprio local onde os alunos moram".

W9 - "Palestras - Seminários - Construção de hortas - Promoção da coleta seletiva".

W10 - "Coleta seletiva do lixo, debates sobre meio ambiente". 


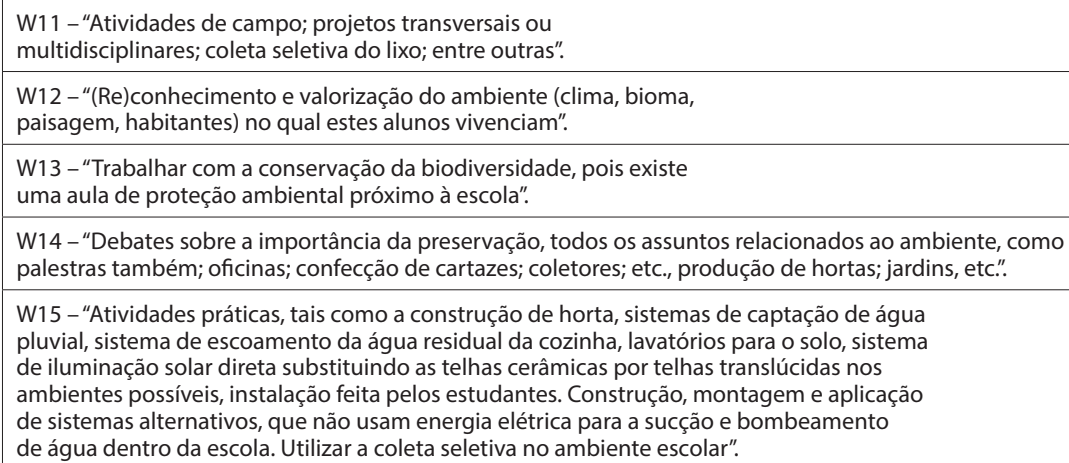

Fonte: Elaborado pelas autoras, 2016.

Percebemos, nos fragmentos acima, que esses professores ainda em formação inicial estão preocupados com a inserção de práticas ambientais no cotidiano escolar atreladas ao contexto geográfico em que os seus alunos vivem, o que corrobora as concepções apresentadas por Reigota (1998). Dado que, para esse autor, a EA tem sido realizada a partir da concepção que se tem de meio ambiente, sendo práticas ambientais meramente preservacionistas. Não obstante, os fragmentos evidenciam uma preocupação excessiva com a preservação dos recursos naturais, como se esta fosse a única forma de direcionar mudanças no comportamento dos alunos para a questão referente à preservação da natureza. Não percebemos, nas falas dos entrevistados, uma preocupação com todas as questões que estão agregadas à temática em torno da $\mathrm{EA}$, tais como os processos históricos, políticos, econômicos e culturais que são inerentes à concepção sobre a conservação da natureza enquanto dimensão central da sobrevivência de todos os seres vivos (OLIVEIRA et al., 2007). Neste contexto, coadunamos com Carvalho et al. (1999), quando dizem que ao se tratar de EA, deve-se considerar fatores econômicos, políticos, sociais, culturais e educacionais, como a continuidade do conhecimento científico, suas possibilidades, falhas e as influências que poderão acarretar à sociedade.

b) Você já conseguiu inserir alguma prática de Educação Ambiental em sua sala de aula? Qual(is)? Cite a(s) mais exitosa(s), em sua opinião.

Conforme os trechos abaixo, referentes às falas dos discentes, percebemos que alguns apresentaram respostas evasivas. No entanto, as falas exprimem opiniões distintas e algumas vezes similitudes entre as concepções que eles nutrem em relação às práticas pedagógicas envolvendo EA. O Quadro 2 exibe as respostas coletadas. 
Quadro 2 - Exemplificação de práticas exitosas em Educação Ambiental na visão dos professores em formação inicial.

\begin{tabular}{|l|}
\hline W1 - "Arborização e Reciclagem". \\
\hline W2 - "Reciclagem de pneus de borracha, transformando-os em jarros de planta". \\
\hline W3 - "Coleta seletiva do lixo; economia de água; economia da energia; não jogar lixo nas ruas, etc.". \\
\hline W4 - "Coleta Seletiva". \\
\hline $\begin{array}{l}\text { W5 - "Sim, com palestra sobre lixo e suas consequências e, logo após, foi realizado } \\
\text { um mutirão com a limpeza de ruas e terrenos próximos à escola". }\end{array}$ \\
\hline $\begin{array}{l}\text { W6 - "Palestra sobre a importância da preservação ambiental, os danos causados pela ação } \\
\text { do homem atualmente, como também em que podemos contribuir para a conservação } \\
\text { do meio ambiente; produção de cartazes informativos e coletores seletivos de lixo". }\end{array}$ \\
\hline $\begin{array}{l}\text { W7 - "Sim, foi feito um cenário com animais empalhados, plantas, mostrando } \\
\text { a importância da conservação do meio ambiente e dos animais". }\end{array}$ \\
\hline $\begin{array}{l}\text { W8 - "[...] fiz todo um cenário na sala de aula, com alguns animais empalhados do Parque } \\
\text { Nacional Serra da Capivara, mostrando a importância de sua preservação". }\end{array}$ \\
\hline $\begin{array}{l}\text { W9 - "Sim. A aplicação de um jogo educacional com a temática meio } \\
\text { ambiente para o 9o ano do Ensino Fundamental". }\end{array}$ \\
\hline $\begin{array}{l}\text { W10 - "Sim. A prática pedagógica utilizando jogos didáticos que chamam a atenção } \\
\text { do aluno para os problemas ambientais de uma forma mais lúdica". }\end{array}$ \\
\hline $\begin{array}{l}\text { W11 - "Confecção de brinquedos pedagógicos com materiais recicláveis, } \\
\text { mostrando que é bom reciclar e aprender ao mesmo tempo". }\end{array}$ \\
\hline $\begin{array}{l}\text { W12 - "[...] levei a turma para conhecer o Parque Serra da Capivara, acompanhados de } \\
\text { condutores regionais e um mateiro, que tem um amplo conhecimento popular das plantas". }\end{array}$ \\
\hline W13 - "Sim. A aplicação de um projeto de educação ambiental". \\
\hline W14 - "Coleta de garrafas PET em torno da comunidade escolar". \\
\hline $\begin{array}{l}\text { W15 - "Ao trabalhar polímeros, fizemos uma pesquisa sobre a reutilização de garrafas } \\
\text { PET, na construção de móveis e a percepção da comunidade local, quanto a estes". }\end{array}$ \\
\hline
\end{tabular}

Fonte: Elaborado pelas autoras, 2016.

As respostas dadas pelos discentes W1,W2, W3 e W4 exibem que eles se mantêm sob influências de práticas sobre EA tradicionais e arraigadas em problemas comuns. Isso reflete que, de qualquer modo, esses professores estão preocupados com os problemas ambientais da contemporaneidade. Os trechos W5 e W6 mostram a necessidade que estes futuros professores possuem de divulgar os problemas ambientais, sobretudo nos aspectos de preservação ambiental para a comunidade escolar, demonstrando que existe uma preocupação pedagógica em relação aos problemas ambientais, ou seja, esses discentes de cursos de licenciatura estão mais reflexivos e críticos sobre o seu papel docente para a sociedade.

As respostas de W7 a W11 mostram que existe uma concepção simbolística para representação dos problemas ambientais ou para reforçar a conscientização destes. Para eles, é necessário criar um "cenário lúdico" para 
promover o interesse dos alunos pelo tema. Sobre isto, Lacerda, Silva e Cleophas (2013) asseguram que as atividades lúdicas são capazes de dinamizar as aulas, a ponto de promover interesse e motivação, aspectos necessários para favorecer um aprendizado mais eficiente perante o ensino de conceitos.

Os fragmentos W1 2 eW13 evidenciam a perspectiva de trabalhar em espaços não-formais, favorecendo, assim, a inserção dos sujeitos dentro do seu próprio meio, porém resgatando ou inserindo valores que os seus alunos desconhecem ou não conseguem considerar importantes. Para Oliveira et al. (2007, p. 484):

Não basta, por exemplo, trabalhar as questões ambientais somente na Semana do Meio Ambiente; é preciso considerar a realidade na qual a escola está inserida e propor discussões acerca das possíveis ações que podem ser implementadas pela comunidade para transformar sua realidade, mudando hábitos e/ ou comportamentos individuais e coletivos, bem como o meio em que vivem.

Os trechos W14 e W15 exibem a preocupação com a reciclagem de garrafas PET, visando à produção de novos produtos ou materiais. Para Grün (1996, p. 47), esta é uma visão meramente capitalista, ou seja:

[...] esta preocupação exacerbada com "nossos recursos" revela um comprometimento com as lógicas capitalísticas. [...] Na verdade, uma proposta de Educação Ambiental que se oriente por esse tipo de diretriz não será mais que uma defesa das condições de produção, ou seja, precisamos ter cuidado para não exaurir "nossos recursos", pois a produção pode ser afetada.

\section{Considerações Finais}

Podemos ressaltar que temáticas relacionadas à realidade dos estudantes e professores, acerca da preservação do Parque Nacional Serra da Capivara, estão sendo consideradas como fonte de preocupação entre os sujeitos participantes desta pesquisa. A maioria dos professores afirmou que "ensinar e aprender Ciências se torna mais atraente quando se utilizam espaços não formais, como, por exemplo, o Parque Nacional Serra da Capivara". Isso mostra que esses professores possuem uma postura crítica-reflexiva acerca de suas atividades e estão dispostos a inserir o território como espaço de contextualização e interdisciplinaridade em suas práticas docentes. E é evidente que ações como essas exigirão mais do professor, mas serão mais enriquecedoras sobre diversos aspectos ligados ao ato de ensinar. 
Sendo assim, podemos destacar que a Educação Ambiental se torna ferramenta indispensável para o processo de Ambientalização da escola. Sua prática deve ser sempre estimulada, e instituída a partir de uma construção coletiva e convidativa, que congregue toda a comunidade escolar. A Ambientalização do espaço escolar é uma fonte de benefícios, tanto para uma melhor compreensão dos conteúdos didáticos, quanto ao estímulo à mudança de atitude dos atores, visando uma prática reflexiva e mais amadurecida rumo à construção de uma cidadania planetária.

A partir de atividades propostas, como essa no âmbito do PIBID, é possível observar nesta nova geração de professores uma sensibilidade quanto às questões pertinentes à Ambientalização: sua importância e complexidade. Através dessa atividade foi possível perceber nestes professores em formação uma disposição à inserção de práticas socioambientais. No entanto, essas ainda estão arraigadas à repetição de práticas ambientais "pontuais" e sem que possam realmente causar mudanças duradouras no contexto social destes indivíduos. No entanto, isto nos mostra a importância eminente da ambientalização curricular, pois, por meio dela, será possível favorecer aos indivíduos uma compreensão do meio ambiente e sua complexidade de modo holístico. Para tanto, é necessário uma internalização da relação entre a atividade humana e o ambiente, de modo a integrar o fator ambiental a sua futura atividade profissional (BOLEA et al., 2004).

Sendo professores de Ciências ainda em formação, é perceptível certa imaturidade teórica e metodológica quanto aos conteúdos em EA. O desconhecimento de mais ações e soluções para os problemas socioambientais que afetam a sua realidade, sobretudo de políticas públicas, também está claro. Cabe às licenciaturas promover um debate mais apurado sobre as abordagens epistemológicas atreladas às concepções da EA, principalmente estimular o conhecimento e conduzir à leitura sobre a vasta bibliografia disponível. Além de inserir, em todas as áreas de conhecimento, temáticas socioambientais, tais como perda da Biodiversidade e preservação dos Recursos Naturais, Mudanças Climáticas, Segurança Alimentar, Segurança Hídrica, dentre outras, em especial evidenciando as questões locais e sua relação com o contexto global. Dessa forma, esperamos fortalecer a mediação dos professores na construção de uma cidadania planetária e igualmente inclusiva, no condizente às questões socioambientais. 
ENVIRONMENTAL EDUCATION IN THE FORMATION OF REFLECTIVE TEACHERS: FROM CONTEXTUALIZED PRACTICES TO THE ENVIRONMNENTALIZATION OF SCIENCE TEACHING

AвSTRACT: Environmental Education contributes to meaningful learning, inserting in pedagogical practices a reflexivity of knowledge construction. Aiming to promote the Environmentalization of learning spaces, many educators introduce new methodologies andapproaches to classroom content. Using the pedagogical practices of the Content Contextualization, the Acquaintanceship with the Environment and the Interdisciplinarity, a research with undergraduates of Natural Sciences course, within the Institutional Bursary Program for the Initiation to Teaching (PIBID), was proposed. The methodology used in the research is the qualitative approach. The aim was to encourage them to adopt different practices in addressing the scientific contents and then reflect on the effectiveness of these practices in promoting Environmentalization and Sustainability at schools. As a result, their disposition to use Piauís landscapes in the contextualization and interdisciplinarity of their teaching practices was revealed.

KEYWORDs: Environmental education. Learning. Environmentalization. Science teaching.

LA EDUCACIÓN AMBIENTAL COMO PROPUESTA DE FORMACIÓN DE PROFESORES REFLEXIVOS: DE PRÁCTICAS CONTEXTUALIZADAS HACIA LA AMBIENTALIZACIÓN EN LA ENSEÑANZA DE LAS CIENCIAS

RESUMEN: La Educación Ambiental ha contribuido de manera significativa con el aprendizaje, introduciendo en las prácticas pedagógicas, una reflexividad en la construcción del conocimiento. Con la intención de promover la Ambientalización de los espacios de aprendizaje, muchos educadores buscan implementar nuevas metodologías al abordar los contenidos en sala de clases. En este sentido, utilizando las prácticas pedagógicas de la Contextualización de los Contenidos Educativos, de la Convivencia con el Medio y de la Interdisciplinariedad, fue realizada una investigación con estudiantes del curso de Ciencias de la Naturaleza, en el ámbito del programa PIBID de la UNIVASF, Piauí, Brasil. La metodología empleada en la investigación es de carácter cualitativo. Los resultados demuestran que estos estudiantes poseen una actitud crítica-reflexiva en relación a las prácticas de Educación Ambiental y manifiestan interés en fomentar la Ambientalización y la Sustentabilidad en el ámbito escolar, estando dispuestos a incluir el territorio como espacio de Contextualización y la Interdisciplinariedad en sus prácticas docentes.

Palabras clave: Educación ambiental. Aprendizaje. Ambientalización. Enseñanza de las ciencias. 


\section{REFERÊNCIAS}

ALARCÃO, I. Formação reflexiva de professores: estratégias de supervisão. Porto: LDA, 1996.

. Professores reflexivos em uma escola reflexiva. São Paulo: Cortez, 2003.

ANDRADE, D. F. Instrumentación de la educación ambiental en las escuelas: un análisis bibliográfico de algunos de sus problemas y posibilidades. Tópicos em Educación Ambiental, México, v.8, n. 3, p. 44-54, 2001.

AUSUBEL, D. P. A aprendizagem significativa. São Paulo: Moraes, 1982.

BERTALANFFY, L. Teoria Geral dos Sistemas. Rio de Janeiro: Vozes, 1977.

BOLEA, Y.; GRAU, A.; DOMINGO, J.; MARTINEZ, H. Ambientalización Curricular de los Estudios de Informática Industrial: la experiencia en la UPC. In: Jornadas de enseñanza universitaria de informática: robótica e informática industrial, 10, 2004, Anais. Alicante: Editora da Universidade de Alicante, 2004. p. 443-451.

BRASIL. Ministério da Educação. Parâmetros Curriculares Nacionais (PCNs). Brasília: MEC/SEB, 2002.

BRITO, A. E. Formar professores: rediscutindo o trabalho e os saberes docentes. In: MENDES SOBRINHO, J. A. C.; CARVALHO, M. A. (Org.). Formação de professores e práticas docentes: olhares contemporâneos. Belo Horizonte: Autêntica, 2006. p. 41-54.

CARVALHO, L. M. et al. Temática ambiental: representações e práticas na escola de $1^{\circ}$ grau. In: BARBOSA, S. R. C. S. (Ed.). A temática ambiental e a Pluralidade do Ciclo de Seminários do NEPAM. Campinas: NEPAM/Unicamp, 1999. p. 329-354.

CLEOPHAS, M. G. Ensino por investigação: concepções dos alunos de licenciatura em Ciências da Natureza acerca da importância de atividades investigativas em espaços não formais. Revista Linhas, Florianópolis, v. 17, n. 34, p. 266-298, maio/ago. 2016.

CLEOPHAS, M. G. P. et al. O Ensino de química e física em espaços não-formais. In: VIII ENPEC - Encontro Nacional de Pesquisa em Educação em Ciências. Anais... Campinas, SP: ABRAPEC, 2011.

.; LINS, W. C. B.; LEÃO, M. B. C. Usabilidade dos dispositivos móveis: verificando a confiabilidade de um questionário a partir da aplicação do coeficiente alfa de Cronbach. In: IX ENPEC - Encontro Nacional de Pesquisa em Educação em Ciências. Anais... Águas de Lindóia, SP: ABRAPEC, 2013.

COMENIUS, I. A. Ditactica Magna. São Paulo: Martins Fontes, 2011.

CORDEIRO, V. J. Prática pedagógica no processo ensino-aprendizagem: um estudo de caso na escola profissionalizante Senac/Concórdia (SC). B. Téc. Senac: a R. Educ. Prof., Rio de Janeiro, v. 36, n.3, p. 65-71, 2010. 
CZAPSKI, S.; TRAJBER, R. Macrocampo de Educação Ambiental. Brasília: Ministério da Educação, 2010.

DEWEY, J. Como pensamos: como se relaciona o pensamento reflexivo com o processo educativo, uma reexposição. São Paulo: Editora Nacional, 1979.

DIAS, G. F. Educação Ambiental: princípios e práticas. 5. ed. São Paulo: Global, 1998.

FAZENDA, I. A Interdisciplinaridade: um projeto em parceria. São Paulo: Loyola, 1993.

FREIRE, P. Política e educação. 5. ed. São Paulo: Cortez, 2001.

GONZÁLES MUÑOZ, M. C. Principales tendencias y modelos de la educación ambiental en el sistema escolar. Revista lbero-americana de Educación, n. 11, p. 13-74, 1996.

GRÜN, M. Ética e educação ambiental: a conexão necessária. Campinas: Papirus, 1996. GUTIÉRREZ, F.; PRADO, C. Ecopedagogía y ciudadanía planetaria. Heredia, Costa Rica: Editorialpec, 1997.

ILLICH. I. Education without School? Lisboa: Editorial Teorema, 1974.

JAPIASSU, H. Interdisciplinaridade e patologia do saber. Rio de Janeiro: Imago, 1976.

LACERDA, P. L.; SILVA, A. C. R.; CLEOPHAS, M. G. P. Dominando a Química: Elaboração e Aplicação de um Jogo como Recurso Didático para o Ensino de Química. In: IX ENPEC - Encontro Nacional de Pesquisa em Educação em Ciências. Anais... Águas de Lindóia, SP: ABRAPEC, 2013.

LUZZI, D. A ambientalização da educação formal. Um diálogo aberto na complexidade de um campo educativo. In: LEFF, E. (Org.). A complexidade ambiental. São Paulo: Cortez, 2003.

MATURANA, H.; VERDEN-ZÖLLER, G. Amar e brincar: fundamentos esquecidos do humano. São Paulo: Palas Athena, 2007.

MORAES, R.; GALIAZZI, M. C. Análise Textual Discursiva: processo reconstrutivo de múltiplas faces. Ciência \& Educação, Bauru, v. 12, n. 1, p. 117-128, 2006.

MORIN, E. Os Sete Saberes necessários à Educação do Futuro. 2.ed. São Paulo: Cortez, 2000.

. A cabeça bem feita: Repensar a reforma repensar o pensamento. 6. ed., Rio de janeiro: Bertrand Brasil, 2002.

NAESS, A. Ecology, Community and Lifestyle. Cambridge: Cambridge University Press, 1982.

NICOLIS, G.; PRIGOGINE, I. Self-organization in non-equilibrium systems. New York: Wiley, 1977.

NÓBREGA, M. L. S.; REIS, E. S.; CARVALHO, L. D. Educação e Convivência com o Semiárido. Juazeiro: Selo Editorial RESAB, 2011. 
. A abordagem do contexto semiárido em sala de aula: experiências de formação docente e inserção didática dos licenciandos em Ciências da Natureza. In: GONDIM, J. P.; PEREIRA, J. G. L. T.; NÓBREGA, M. L. S. (Org.). Construindo saberes: articulando as práxis pedagógicas em sala de aula. Juazeiro: Selo Editoria RESAB, 2012.p. 81-92.

;iNASCIMENTO, E. P. Ambientalização acadêmica e a cultura da sustentabilidade nas universidades. Revista Pós-Ciências Sociais. São Luiz: UFMA, no prelo.

OLIVEIRA, A. L. et al. Educação ambiental: concepções e práticas de professores de ciências do ensino fundamental. Revista Electrónica de Enseñanza de las Ciencias, v. 6, n.3, p. 471-495, 2007.

ONU. Declaração da Conferência de Tbilisi. Nova York: Organização das Nações Unidas (ONU), 1977.

PELIZZARI, A. et al. Teoria da aprendizagem significativa segundo Ausubel. Rev. PEC, Curitiba, v. 2, n. 1, p. 37-42, 2002.

REIGOTA, M. Meio ambiente e representação social. 3. ed. São Paulo: Cortez, 1998.

ROCHA, S. C. B.; FACHÍN-TERÁN, A. O uso de espaços não-formais como estratégia para o ensino de Ciências. Manaus: UEA edições, 2010.

SANTOMÉ, J. Globalização e Interdisciplinaridade: o Currículo Integrado. Porto Alegre: Artes Medicas Sul, 1998.

SENGE, P. M. et al. A quinta disciplina - caderno de campo: estratégias para construir uma organização que aprende. Rio de Janeiro: Qualitymark, 1994.

SILVEIRA, H. E. Mas, afinal: o que é iniciação à docência? Atos de Pesquisa em Educação, Blumenau, v. 10, n. 2, p. 354-368, maio/ago. 2015.

SOARES, M. Letramento: um tema em três gêneros. 1. ed. Belo Horizonte, Autêntica, 2001.

TARDIF, M. Saberes docentes e formação profissional. 4. ed. Petrópolis, RJ: Vozes, 2002.

Maria LuCiana da Silva Nóbrega: Doutoranda em Desenvolvimento Sustentável pelo CDS/UNB (Centro de Desenvolvimento Sustentável/ Universidade de Brasília). Bolsista de formação de Doutorado da Fundação de Amparo à Pesquisa do Estado do Piauí. Professora Assistente e Pesquisadora da Universidade Federal do Vale do São Francisco (UNIVASF), Colegiado de Ciências da Natureza (CCINAT), Câmpus Serra da Capivara/PI. Líder do Núcleo de Estudos em Sustentabilidade e Ambientalização (NESAVUNIVASF). Colaboradora da Rede de Educação do Semiárido Brasileiro (RESAB) (desde 2006).

E-mail: luciana.nobrega@univasf.edu.br 
Maria das GraçAs Cleophas: Doutora em Ensino das Ciências pela Universidade Federal Rural de Pernambuco (UFRPE) e professora adjunta do Instituto Latino-Americano das Ciências da Vida e da Natureza (ILACVN) da Universidade Federal da Integração Latino-Americana (UNILA), Foz do Iguaçu/PR. Coordena o Núcleo de Desenvolvimento de Pesquisas em Ensino de Química (NuDPEQ).

E-mail:maria.porto@unila.edu.br 